\title{
RELATIONSHIP OF BEHAVIOURAL INTENTIONS WITH ACADEMIC KNOWLEDGE TRANSFER BEHAVIOUR
}

\author{
Siti Nur Shahira Dahari ${ }^{1}$ and Rosalie Hall ${ }^{2}$ \\ ${ }^{1}$ Ms., Durham University, United Kingdom, dahari.s.shahira@durham.ac.uk \\ ${ }^{2}$ Prof., Durham University, United Kingdom, rosalie.hall@durham.ac.uk
}

\begin{abstract}
The current study investigated attitudinal components that potentially impact the Knowledge Transfer Behaviour (KTB) of academics. It focused specifically on the role of behavioural intentions in the academic research process, and the resulting knowledge productivity, utilising a large sample of academics from a Malaysian Public University. The study contributes theoretically and empirically by demonstrating the relationships of the variables comprising the Theory of Planned Behaviour (i.e. attitudes, subjective norms, perceived behavioural control and intentions) on performance outcomes related to Knowledge Transfer Behaviour. The study also has practical significance based on its implications for university faculty members, providing suggestions for better understanding of how they might increase their success at Knowledge Transfer activities. This study adopts a quantitative method, using online questionnaires as the instruments for data collection. The on-line survey was administered by emailing potential respondents a link. Volunteer respondents were academics from Malaysia Public University $(N=985)$. Path analysis was conducted to test the research hypotheses, using a structural equation modelling (SEM) approach. The results revealed that behavioural intentions significantly predicted KTB, and Attitude and PBC significantly predicted Behavioural Intentions. Unexpectedly, Subjective Norms did not predict behavioural intentions for Knowledge Transfer Behaviour (KTB) of academics. When further modifications were made to the model, Knowledge Transfer behaviour was predominantly uniquely explained by perceived behavioural control. Further recommendations were made for this study by adding other theories such as concept of the Triple Helix by looking upon university, industry and government relationships for expanding further research. Moreover, shedding light on the findings of this study could add valuable information to other researchers and thus contributes theoretically and empirically in Theory of Planned Behaviour literature.
\end{abstract}

Keywords: Knowledge Transfer, Theory of Planned Behaviour and Academic research productivity.

\section{INTRODUCTION TO KNOWLEDGE TRANSFER BEHAVIOR (KTB)}

In this dynamic, knowledge-based society, enhancing productivity has taken on more significance in the recent study on performance and outcomes (Ka"pyla" et al., 2010). This is especially true for higher higher education institutions focusing on knowledge activities which can be found in universities research activities and outcomes (Flagg et al., 2011; Levitan \& Ray, 1992; Long et al., 1998). According to Dev (2010), by continuously involvement with creation of new knowledge and able to disperse and make use of it widely through their operations and systems make a educational institutions thriving accomplishment. Indeed, the creation and transmission of knowledge are recognized as key performance indicators for most higher 
education institutions universities globally.

This can be seen in Knowledge Transfer activities which involve documentation and communication (Disterer, 2001). In higher education settings, the conveyance and transmission of scholarly knowledge is commonly done in a variety of ways including through informal social interactions, formal presentations at events such as lectures and conferences, and the production of documents such as technical reports, books, and journal articles. Tacit knowledge that exists within individual academics becomes explicit as it is communicated verbally or in documents to students, colleagues or practitioners.

Knowledge Transfer activities in academic settings involve the conduct of original research activities, the provision of training and teaching (e.g., learning activities), and the documentation and/or publication of explicit knowledge and transmission of explicit and tacit knowledge both to colleagues and research team members, as well as outsiders (Molas-Gallart et al. 2002; D'Este \& Patel, 2007; Abreu \& Grinevich, 2013 ). The current study focuses on all facets of research, including the dissemination of research knowledge. These research-related Knowledge Transfer activities may be carried out by academics acting alone or commissioned in some manner by non-academic organizations.

\section{LITERATURE REVIEW}

In the current empirical study, the author adopts Ajzen's (1991) Theory of Planned Behaviour (TPB) as a theoretical basis for predicting the extent to which academic staff engagement in Knowledge Transfer Behaviours (KTB). According to Ajzen (1991), the Theory of Planned Behaviour suggests an individual's intention to perform a given behaviour depends upon individual attitude towards that behaviour, in conjunction with subjective norms and perceptions of behavioural control. As higher degree intention of individual, the more likely will increase the specific behaviour performance tendency (Ajzen, 1991).

To date, the Theory of Planned Behaviour (TPB) has represent and been widely used in prediction of intentions and behaviours across multiple studies context (Harrison, Mykytyn, \& Riemenschneider, 1997; Mutaz, 2013), with disciplines ranging from computer science (Siponen, 2000), management (Ye, Chen \& Jin, 2006), marketing and consumer behaviour (Ajzen, 2011; Kalafatis, 1999), sociology (Kim \& Karpova, 2007), information systems (Huang \& Chuang, 2007), and technology adoption and use (Dickinger, Arami, \& Meyer, 2008; Titah Riyadh \& Henri Barki, 2009), as well as many others.

The Theory of Planned Behaviour posits that specific behaviours are more likely to result when individuals hold strong behavioural intentions for them. For purposes of the current study, Behavioural Intention specifically refers to a person or human intention engaging in a set of behaviours that we call Knowledge Transfer Behaviours, i.e., activities that lead to consultancy, training and research activities. The strength of behavioural intentions, in turn, depends upon three factors; an individual's attitude based upon specific activities, subjective norms associated upon behaviour, and the perceived behavioural control of the individual who might engage in the behaviour (Ajzen, 1991).

More specifically, Attitude is refers as extent upon an individual has a favourable or unfavourable orientation towards a set of specific Knowledge Transfer Behaviour activities. Subjective norm is defined as extent upon individual perceives various Knowledge Transfer Behaviour activities as expected among their norms surroundings especially those play important role to the individual and associated with. Perceived behavioural control is described as the capacity of control an individual judgement that he or she will have when undertaking Knowledge Transfer Behaviour activities.

The theoretical model in Figure 1 summarizes the key variables that were studied and the proposed relationships amongst them. Related hypotheses are stated below the figure.

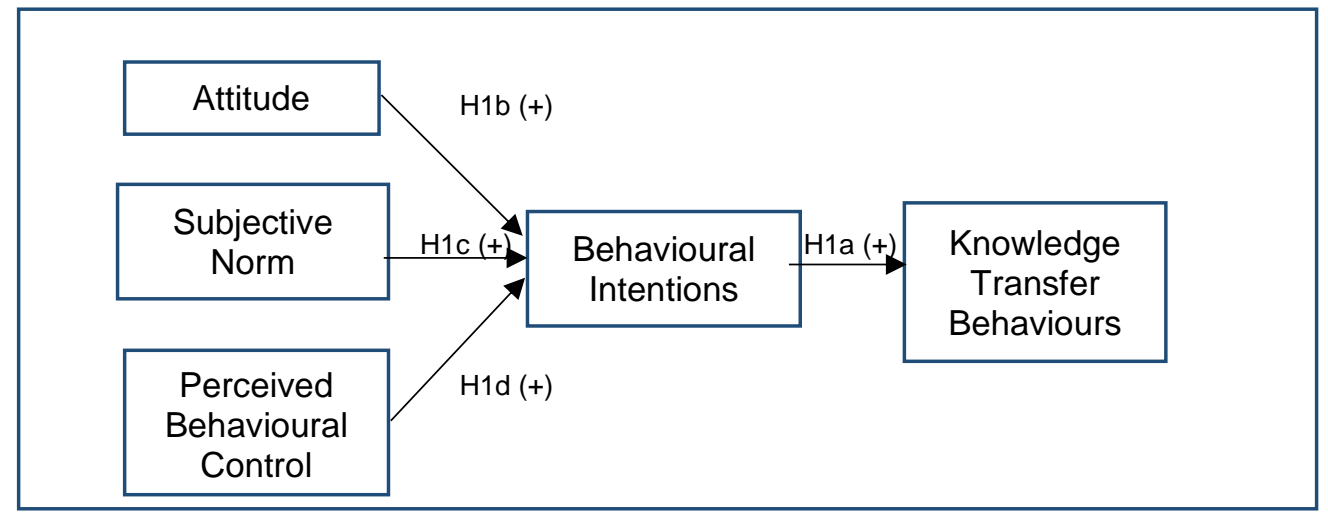

Figure 1: Model 1 of Knowledge Transfer Behaviour (KTB). 
H1: The Theory of Planned Behaviour components predict academics' tendencies to engage in Knowledge Transfer Behaviours. More specifically:

H1a. Behavioural Intentions have a direct, positive effect on KTB.

H1b. Attitude has a positive effect on KTB via Behavioural Intentions.

H1c. Subjective Norms have a positive effect on KTB via Behavioural Intentions.

H1d. Perceived Behavioural Control has a positive effect on KTB via Behavioural Intentions.

\section{METHODOLOGY AND RESULTS}

\subsection{Methods}

A quantitative survey methodology was used. The questionnaire was administered by emailing potential respondents a link to an online survey administered by SmartSurvey. A total of one thousand and eleven (1011) volunteer respondents (academics) from Malaysia Public University were involved. Prior to conducting the primary analyses however, this sample size was reduced in the data cleaning process (i.e., eliminating non-research positions and careless/incomplete responses), resulting in useable sample of $\mathrm{N}=$ 985.

The Theory of Planned Behaviour (TPB) items used to measure each of the items constructs was formulated to fit the academic context of the study following procedures described in Ajzen (2006). These items were then pilot tested with an academic sample, resulting in items measuring: Attitude (7 items), Subjective Norms (9 items), Perceived Behavioural Control (PBC: 7 items), and Behavioural Intentions (7 items). Responses to all TPB items were made using a 7-point response format. For example, an attitudinal item is "The effect on my career of presenting and publishing peer-reviewed research papers is likely to be," and the 7 point response had anchors of "agree:_1_2_3_4_5_6_7_: disagree".

Eight Knowledge Transfer Behaviour (KTB) items were also developed by the researcher after consulting conceptually similar measures used in existing research (e.g. Bok \& Kim, 2002; Huang, 2014; Dahari, et. al., 2014; Hsu, et. al., 2001), then modifying them as needed to fit the academic context of the current study. The resulting items were then pilot tested. All item responses were made using a 5-point Likert-style response format indicating the frequency with which specific Knowledge Transfer Behaviour was engaged in. An example of an item developed to measure Knowledge Transfer is, "I worked on one or more books or book chapters reporting my research findings". The responses were ranged from ' $1=$ not at all; $2=1-2$ times this past 12 months; $3=1-2$ times per semester; $4=1-2$ times most months and $5=1-2$ times most weeks.'

SPSS version 20 was used to perform descriptive analysis of the data. Reliability estimation (Cronbach's alpha) was carried out to analyse the consistency of all scales. In addition, Mplus v. 6.12 (Muthén \& Muthén, 1998-2017) was used to estimate latent variable path models used to test the specific hypotheses.

\subsection{Descriptive Analyses}

Table 3.2, summarizes the means, standard deviations, correlations, and reliabilities for all study variables. All focal variables had good reliability, with alphas ranging from .84 to .94 . Furthermore and as would be expected from the model, the results show a strong positive correlation between the TPB variables and KTB, with pearson correlations in the range of .26 and above.

Table 3.2: Means, standard deviations, correlations, and reliabilities for study variables

\begin{tabular}{|c|l|c|c|c|c|c|c|c|}
\hline & & $\mathrm{M}$ & $\mathrm{SD}$ & 1 & 2 & 3 & 4 & 5 \\
\hline 1 & Knowledge Transfer Behaviours & 2.21 & .75 & .92 & $.39^{* *}$ & $.30^{* *}$ & $.26^{* *}$ & $.50^{* \star}$ \\
\hline 2 & Behavioural Intentions & 5.70 & 1.02 & & .94 & $.65^{\star *}$ & $.55^{\star *}$ & $.68^{\star *}$ \\
\hline 3 & Attitude & 6.11 & .74 & & & .87 & $.61^{* *}$ & $.45^{\star *}$ \\
\hline 4 & Subjective Norm & 5.50 & .84 & & & & .84 & $.51^{* \star}$ \\
\hline 5 & Perceived Behavioural Control & 5.10 & 1.04 & & & & & .88 \\
\hline
\end{tabular}

Note. Values of Cronbach's alpha are reported on the matrix diagonal.

\subsection{Latent Variable Path Analysis}

To test the research hypotheses, a latent variable path model consistent with Figure 1 was specified. In this 
model (M1), latent constructs were specified for each of the four Theory of Planned Behaviour (TPB) variables, and for Knowledge Transfer Behaviour. Item parcels were used as measured indicators for each of the TPB constructs ( 3 item parcels each), and the four item-level responses were used as indicators for the Knowledge Transfer Behaviour (KTB) construct. In the initial model, Behavioural Intentions directly influenced Knowledge Transfer Behaviour, and the effects of Attitudes, Subjective Norms, and Perceived Behavioural Control on KTB were modelled as fully mediated through Behavioural Intentions.

Overall, all fit indices except for the statistically significant chi-square value, suggest that this initial model fit the data fairly well, with $X^{2}=1155.016, d f=194, p<.0001, R M S E A=.081, C F I=.921, S R M R=.116$. A meaningful amount of variance in Knowledge Transfer Behaviours, $R^{2}=.18, p<.001$, was explained by the model. The model also explained substantial variance in behavioural intentions, $R^{2}=.73, p<.001$. The estimates of the path coefficients from this model are listed in the top section of Table 3.3.

The results for Model 1 show, as proposed, that Behavioural Intentions significantly predicted KTB, and also that Attitude and PBC significantly predicted Behavioural Intentions. However, Subjective Norms did not predict behavioural intentions. In addition, the tests of the mediated (i.e., indirect) effects of Attitude on KTB (standardized $a b=.16, p<.001$ ) and of PBC on KTB (standardized $a b=.23 p<.001$ ) indicated that both of these indirect effects carried through Behavioural Intentions were statistically significant. Thus, results of this model were broadly supportive of the classical Theory of Planned Behaviour, with the exception of the null effect of subjective norms.

Table 3.3: Path coefficients from initial SEM model ( $D V=K T B$ factor).

\begin{tabular}{|l|c|c|c|c|c|}
\hline & \multicolumn{3}{|c|}{ Unstandardized Coefficients } & Std. Coeff. \\
\hline Model \& Paths & $B$ & se & $p$ & $\beta$ \\
\hline Model 1 (Hypothesized Model) & & & & \\
\hline Behavioural Intentions to KTB & .28 & .02 & $<.001$ & .42 \\
\hline Attitude to Behavioural Intentions & .52 & .06 & $<.001$ & .36 \\
\hline Subjective Norm to Behavioural Intentions & .06 & .07 & .47 & .04 \\
\hline PBC to Behavioural Intentions & .60 & .05 & $<.001$ & .54 \\
\hline & & & & & \\
\hline Model 2 (Frees direct PBC path) & & & & & \\
\hline Behavioural Intentions to KTB & -.21 & .05 & $<.001$ & -.32 \\
\hline PBC to KTB & .66 & .07 & $<.001$ & .90 \\
\hline Attitude to Behavioural Intentions & .49 & .06 & $<.001$ & .36 \\
\hline Subjective Norm to Behavioural Intentions & .08 & .07 & .30 & .05 \\
\hline PBC to Behavioural Intentions & .59 & .05 & $<.001$ & .54 \\
\hline
\end{tabular}

Note. $\mathrm{KTB}=$ Knowledge Transfer Behaviour; PBC $=$ Perceived Behavioural Control.

However, the initial model had a large modification index $(\mathrm{MI}=109.248)$ for adding the direct effect of PBC on KTB, in addition to the mediated effect (through Behavioural Intentions) that was present in the hypothesized model. This new model (M2) fit the data better than did the previous model, $X^{2}=1013.296, d f=$ $193, p<.0001, R M S E A=.064, C F I=.971, S R M R=.036$. In Model 2, the variance explained in Behavioural Intentions stayed the same as for Model 1, as would be expected. However, the variance explained in KTB increased to $R^{2}=.47 p<.001$. In Model 2, once the additional direct effects of PBC were included, again the effect of Subjective Norm towards Behavioural Intentions still was not statistically significant, as can be seen in the second set of parameter estimates in the bottom half of Table 3.3.

\subsection{Summary of Results}

Table 3.4 shows the conclusions with respect to hypothesis testing based on the estimation of Model 1 , again indicating that all except $\mathrm{H} 1 \mathrm{C}$ were supported in this model. Moreover, these results should be interpreted in light of the results of testing exploratory Model 2, which indicated that even when Perceived Behavioural Control was allowed to have direct, as well as mediated, effects on Knowledge Transfer Behaviours, the high relationship of PBC with the remaining predictors and mediator variable does not change significant effects as in Model 1, yet again the effect of Subjective Norm towards Behavioural Intentions still was not statistically significant on KTB. 
IJASOS- International E-Journal of Advances in Social Sciences, Vol. III, Issue 8, August 2017

Table 3.4: Summary of Model 1 Hypothesis Testing

\begin{tabular}{|c|l|c|c|}
\hline \multicolumn{1}{|c|}{ Statement of hypotheses } & $\begin{array}{c}\text { Significance } \\
\text { Value }\end{array}$ & Result \\
\hline H1a & $\begin{array}{l}\text { Behavioural Intentions have a direct, positive effect } \\
\text { on KTB }\end{array}$ & $<.001$ & Supported \\
\hline H1b & $\begin{array}{l}\text { Attitude has a positive effect on KTB via Behavioural } \\
\text { Intentions }\end{array}$ & $<.001$ & Supported \\
\hline H1C & $\begin{array}{l}\text { Subjective Norms have a positive effect on KTB via } \\
\text { Behavioural Intentions. }\end{array}$ & .47 & Not supported \\
\hline H1d & $\begin{array}{l}\text { Perceived Behavioural Control has a positive effect } \\
\text { on KTB via Behavioural Intentions. }\end{array}$ & $<.001$ & Supported \\
\hline
\end{tabular}

\section{CONCLUSION AND RECOMMENDATION}

Overall in this study, there is a suggestion with the results from Model 1 that Attitude and Perceived Behavioural Control influence academics' Knowledge Transfer Behaviour (KTB) through their effects on Behavioural Intentions. However, estimation of an exploratory model which adds a direct path from PBC to KTB suggests that for these academics, a key component of the Theory of Planned Behaviour (TPB) model is their perceptions of the controllability of the activities that allow them to engage in Knowledge Transfer, to the extent that this variable appears to overwhelm the effects of other components of the TPB model.

This result suggests a practical implication, namely, that an effective way to increase the Knowledge Transfer Behaviours of academics might be to increase their perceived control over factors needed to engage in the relevant behaviours, likely to be done by increasing their actual control over such behaviours. It is hoped that this study can bring insight by adding our knowledge on the Theory of Planned Behaviour. Other than that, this study also can add other theories such as concept of the Triple Helix by looking upon university, industry and government relationships for expanding further research and increase more precise and details results on the academics Knowledge Transfer Behaviour. In addition, shedding light on the findings of this study could add valuable information to other researchers and thus contributes theoretically and empirically in Theory of Planned Behaviour literature.

\section{REFERENCE LIST}

Abreu, M. \& Grinevich, V. (2013). The nature of academic entrepreneurship in the UK: Widening the focus on entrepreneurial activities. Research Policy, 42(2), 408- 422

Ajzen, I. (1991). The theory of planned behaviour. Organizational Behaviour and Human Decision Processes, 50 (2), 179-211.

Ajzen, I. (2006). Constructing a TPB Questionnaire: Conceptual and Methodological Considerations. http://www.uni-bielefeldyh.de/ikg/zick/ajzen\%20 construction\%20a\%20tpb\%20questionnaire.pdf

Ajzen, I. (2011). Attitudes, personality and behavior. Maidenhead, England: McGraw-Hill/Open University Press.

Bock, G.-W., \& Kim, Y.-G. (2002). Breaking the myths of rewards: An exploratory study of attitudes about knowledge sharing. Information Resources Management Journal, 15, 2, 14-21.

Dahari, S. N. S. B., Rahman, A. L. B. A., Sawal, M. Z. H. B. M., \& Tanuri, Z. A. B. M. (2014). Librarian knowledge productivity behaviour: A conceptual model. In The Role of Service in the Tourism and Hospitality Industry - Proceedings of the 2nd International Conference on Management and Technology in Knowledge, Service, Tourism and Hospitality, SERVE 2014. (pp. 209-213). CRC 
Press/Balkema.

D'Este, P., \& Patel, P. (2007). University-industry linkages in the UK: What are the factors underlying the variety of interactions with industry? Research Policy,36(9), 1295-1313.

Dev Raj Adhikari, (2010). Knowledge management in academic institutions. International Journal of Management Review, 41 (2), 79-94.

Dickinger, A., Arami, M. \& Meyer, D. (2008) European Journal of Information Systems, $17: 4$. doi:10.1057/palgrave.ejis.3000726

Disterer, G. (2001). Individual and social barriers to knowledge transfer. Journal of Business Administration, $34(1), 1-7$.

Flagg, D., Gilley, O. \& Park, J. (2011). Job market signalling: What drives the productivity of finances Ph.D.s?. Financial Management, 40, 483-513.

Harrison, D. A., Mykytyn, P. P., \& Riemenschneider, C. K. (1997). Executive decisions about adoption of information technology in small business: Theory and empirical tests. Information Systems Research, 8(2), 171-195.

Hsu, M.-H., Ju, T. L., Yen, C.-H., \& Chang, C.-M. (January 01, 2007). Knowledge sharing behavior in virtual communities: The relationship between trust, self-efficacy, and outcome expectations. International Journal of Human - Computer Studies, 65, 2, 153-169.

Huang, E., \& Chuang, M. (2007). Extending the theory of planned behaviour as a model to explain postmerger employee behaviour of IS use. Computers in Human Behavior, 23 (1), 240-257.

Huang, Y.-H. (September 01, 2014). Measuring individual and organizational knowledge activities in academic libraries with multilevel analysis. The Journal of Academic Librarianship, 40, 5, 436-446

Ka"pyla“, J., Ja"a"skela"inen, A. \& Lo"nnqvist, A. (2010). Identifying future challenges for productivity research: evidence from Finland. International Journal of Productivity and Performance Management, 59, 607-23.

Kalafatis, S., Pollard, M., East, R., \& Tsogas, M. (1999). Green marketing and Ajzen's theory of planned behaviour: A cross-market examination. Journal of Consumer Marketing, 16 (5), 441-460.

Kim, H. \& Karpova, E., (2010). Consumer attitudes toward fashion counterfeits: application of the theory of planned behaviour. Clothing and Textiles Research Journal 28 (2), 79-94.

Levitan, A.S. \& Ray, R. (1992), "Personal and institutional characteristics affecting research productivity of academic accountants", Journal of Education for Business, 67, 335-41.

Long, R., Bowers, W., Barnett, T. \& White, M. (1998), "Research productivity of graduates in management: effects of academic origin and academic affiliation", Academy of Management Journal, 41, 704-14.

Molas-Gallart, J., Salter, A., Pastel, P., Scott, A. \& Duran, X. (2002). Measuring Third Stream Activities. Final Report to the Russell Group of Universities. Science and Technology Policy Research (SPRU), University of Sussex. Brighton (UK).

Mutaz M Al-Debei, Enas Al-Lozi, \& Papazafeiropoulou, A. (2013). Why people keep coming back to Facebook: Explaining and predicting continuance participation from an extended theory of planned behaviour perspective. Decision Support Systems 55, 43-54.

Muthén, L.K., \& Muthén, B.O. (1998-2017). Mplus User’s Guide. Eighth Edition. Los Angeles, CA: Muthén \& Muthén.

Sh. Ye, Chen, H. \& Jin, X. (2006). Exploring the moderating effects of commitment and perceived value of knowledge in explaining knowledge contribution in virtual communities. The Tenth Pacific Asia Conference on Information Systems (PACIS), 2006.

Siponen, M. (2000). A conceptual foundation for organizational information security awareness, Journal of Information Management and Computer Security 8 (1), 31-41.

Titah, R., \& Barki, H. (January 01, 2009). Nonlinearities between attitude and subjective norms in information technology acceptance: A negative synergy?. MIS Quarterly: Management Information Systems, 340, 4, 827.

Triple-helix. Retrieved from https://triplehelix.stanford.edu/3helix_concept 